\title{
Microbial Inoculation as a Tool in Livestock Farming
}

\section{ISSN: 2637-7659}

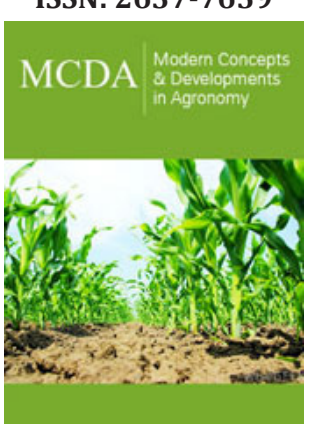

*Corresponding author: Efimia M Papatheodorou, 3Department of Ecology, School of Biology, Faculty of Science, Aristotle University of Thessaloniki, 54124 Thessaloniki, Greece

E-mail: papatheo@bio.auth.gr

Submission: 师 September 19, 2019

Published: 眥October 03, 2019

Volume 5 - Issue 2

How to cite this article: Nantsios T, Monokrousos N, Papatheodorou EM. Microbial Inoculation as a Tool in Livestock Farming. Mod Concep Dev Agrono.5(2). MCDA.000608.2019.

DOI: 10.31031/MCDA.2019.05.000608

Copyright@Efimia M Papatheodorou, This article is distributed under the terms of the Creative Commons Attribution 4.0 International License, which permits unrestricted use and redistribution provided that the original author and source are credited.

\author{
Nantsios $\mathrm{T}^{1}$, Monokrousos $\mathrm{N}^{1,2}$ and Papatheodorou EM${ }^{1,3 *}$ \\ ${ }^{1}$ International Hellenic University, Greece \\ ${ }^{2}$ Department of Soil Science of Athens, Greece \\ ${ }^{3}$ Department of Ecology, Greece
}

\begin{abstract}
The increased demand for food creates the necessity for increased production of edible plants and livestock. Further, the demand for the implementation of environmentally friendly methods in agriculture, leads to the replacement of chemical fertilizers with alternatives. In order an enhanced crop production to be achieved, research on the use of microorganisms that affect positively the soil environment and plants' growth is of urgent need. Such microorganisms are called microbial inoculants and contain the plant growth promoting rhizobacteria (PGPR), the arbuscular mycorrhizal fungi (AMF) and the endophytes. This review focused on the effects of microbial inoculants' application on the most commonly fodder plants as maize (Zea mays), wheat (Triticum aestivum), barley (Hordeum vulgare), oats (Avena sativa), soybean (Glycine max), sorghum (Sorghum spp.), alfalfa (Medicago sativa) and trefoil (Trifolium spp.). A survey of the literature for the period 2010-2018 was applied.
\end{abstract}

Totally 72 articles were collected; 60 of them were referred to only four plant species (maize, wheat, barley and soybean). We categorized the articles in relation to the type of microbial inoculant used per se or jointly (PGPR, AMF and endophytes) and also in relation to the environmental conditions under consideration (stress, pollution, nutrient deficiency or unstressed conditions). $45 \%$ of the studies examined the PGPR individual effects, $22 \%$ the effects of AMF and $20 \%$ those of endophytes. PGPR promote plant growth in terms of root and aerial parts parameters, yield production, nutrient uptake and alleviate from stressful environmental conditions. Endophytes were applied mainly under non-stressed conditions and were studied in relation to their ability to protect plants against pathogens. However, the role of microbes as protective agents against diseases was examined in only $3 \%$ of the studies. We suggested that in the area of fodder plants cultivation, research focusing on the role of microbial inoculants as biopesticides is of urgent need.

Keywords: PGPR; AMF; Endophytes; Biofertilizers; Biopesticides

\section{Introduction}

According to FAO, the global population will reach 9.1 billion by $2050,34 \%$ higher than today, and the majority of this increase will be in developing countries [1]. Food production and especially meat production has to be greater by $70 \%$ in order to cover the elevated needs of feed of the new world's population [2]. Cereal production has to reach the limit of 3 billion tones and the meat quantity to be increased by more than 200 million tones per year [2,3]. Higher crop yield, better quality, biotic and abiotic stress resistance, expression of various desirable agronomic traits, better and wider adaptability of crops to climatic changes are signs of crop yield's improvement [4]. Quantity can be defined as the amount of grains or seeds that is generated from a unit of land expressed as $\mathrm{Kg} / \mathrm{ha}$ and actually represents the agricultural output. Referring to quality, we must consider the water content of the product, the dry matter (organic and inorganic) and the concentration of carbohydrates, fats, proteins, minerals and vitamins $[5,6]$.

In order animals to cover their life cycle, they need to intake various chemical compounds which are mainly carbohydrates, protein, fats, minerals and vitamins [7]. Apart from proteins, some lipids and some minerals contribute to the formation of main structures of the body tissues acting towards the renewal of the body units and the formation of muscles (meat), eggs and milk. Moreover, some minerals and vitamins which cannot be synthesized inside the animal body promote the function and completion of basic metabolic pathways that are involved in the provision of energy or the construction of main body tissues. Water is a basic 
component of animals' body as it constitutes the $55 \%-80 \%$ of their total live weight.

It affects the main chemical reactions and is the main component of blood, lymph and animal products such as milk, urine and feces [5]. Fodder crops are those that are cultivated for animal nutrition. These crops include cereals, legumes and grasses that are fed to animals as green plants, hays or silage after the proper procedure [8]. The most cultivated crops worldwide are corn, wheat, rice, barley and oats [9]. All these crops are used for livestock farming, except from rice which is fed to animals in a lower scale [9]. In USA, the main cereals used for the animal nutrition in 2016 were corn (50\%), soybean, bakery meals and sorghum [10]. Alfalfa constitutes the fourth most cultivated crop in U.S.A. [11] while high quality Trifolium spp. is a major food source for animals worldwide [12]. As it is revealed, the main crops used for the nutrition of livestock animals are maize (Zea mays), wheat (Triticum aestivum), barley (Hordeum vulgare), oats (Avena sativa), soybean (Glycine max), sorghum (Sorghum spp.), alfalfa (Medicago sativa) and trefoil (Trifolium spp) [10]. During the last decades, farmers seem to prefer the use of alternatives instead of chemical fertilizers in order to improve crop productivity and quality, as they are considered friendlier to the environment and economically efficient [13].

Such agents are the microbial inoculants that can be classified either as biocontrol agents or biofertilizers [14]. The main action of biofertilizers is the plant growth promotion by increasing the availability of nutrients, the root biomass and area and the uptake of nutrients after their application on the seed, the surface of the plant or even into the soil $[14,15]$. There are three main categories of microbial inoculants which have been extensively studied,

a) the free-living bacteria that contain the plant growth promoting rhizobacteria (PGPR) and bacteria (PGPB),

b) the fungi and

c) the endophytes $[14,15]$.

It has been demonstrated that the enhancement of plant growth and yield due to microbial inoculation resulted from the elevated nutrient uptake and the improvement of the nutrient status of the inoculated plant $[14,16]$. Some inoculants are capable of solubilizing nutrients via the production of organic acids and phosphatases $[14,17,18]$ making nutrients available to the plants [13]. PGPR affect the growth of the plants directly by producing phytohormones or indirectly by acting as control agents or by being involved in the availability of nutrients $[13,19]$. Moreover, free-living and symbiotic bacteria provide $\mathrm{N}$ through the fixation of atmospheric $\mathrm{N}$ and the production of hormones such as auxins, cytokinins, gibberellins and ethylene $[14,20]$. Usually, the combination of these hormones gives better results than their individual action [14]. Further, PGPR could induce systemic resistance against various bacteria, fungi and viruses [21]. This review aimed to monitor the use of microbial inoculants in fodder crops and their effects on plants under specific environmental conditions. It was focused on the eight crop species that are mainly used for livestock farming.

\section{Method}

A review of literature published from 2013 until July 2018 for maize and from 2010 until 2018 for the rest plants was organized. This differentiation in research datum concerning maize was due to the large number of review papers referring to maize till 2013 which formed the need for more recent information. The search of literature was based on Science Direct, Web of Science and Scopus databases. The search terms used were: (maize* or Zea mays* or wheat* or Triticum aestivum* or barley* or Hordeum vulgare* or sorghum* or Sorghum spp* or oat* or Avena sativa* or soybean* or Glycine max $^{*}$ or alfalfa* or Medicago sativa* or trefoil* or Trifolium $s p p^{*}$ ) and (PGPR* or PGPF* or AMF* or endophytes*) or (name of plant) and (drought stress* or salinity* or yield improvement* or crop production* or quality improvement*). We focused on articles where the effects of microbial inoculants on plants under different environmental conditions (stress, pollution, nutrient deficiency or unstressed cultivation conditions) were examined. Totally, 72 articles were identified using the criteria. 60 of these articles were referring to only four plants, specifically maize, wheat, barley and soybean, while the rest 12 referred to the rest four plants: sorghum, oats, alfalfa, trifolium. We categorized the papers in two subcategories. Firstly, in relation to the type of microbial inoculant used per se or jointly (PGPR, AMF and endophytes). Further, the studies were categorized in relation to the environmental conditions under consideration (stress, pollution, nutrient deficiency or unstressed environmental conditions).

\section{Result}

From the total of 72 studies, 26 concerned maize, 17 wheat, nine soybean, six barley, five sorghum, four alfalfa, one trefoil and one oats. There were also two studies where more than one crop was considered. Clearly, the plant growth promoting rhizobacteria (PGPR) are of main interest of research since 2010 as they are represented in almost half $(27 / 72)$ of the papers selected (Figure 1). The AMF effects have been extensively analyzed the period before 2010 and many review papers have been written [18,22,23]. This is the reason of their limited contribution to results $(13 / 60)$. Almost the same percentage with the AMF studies, covered the studies of endophytes (12/60). The application of combined inocula of microbes was studied in even less papers, mostly referring to the combination of PGPR and AMF whereas the combination of endophytes with AMF did not attract special attention till now (Figure 1). Further we categorized the articles in relation to conditions under study; environmental stresses as drought, salinity or temperature extreme.

As pollution we defined the cases with toxicity or surplus of heavy metals or other elements. Moreover, we categorized as nutrient deficiency or fertilization the articles where plants' inoculation takes place in soils with limited or very low concentrations of one or more elements. In most cases, the application of microbial inoculation has been studied under conditions of abiotic stress, nutrient deficient or toxic soil conditions. So, the main concern was the alleviation of the adverse conditions and the improvement 
of agroecosystems. The effects of inoculation in non-stressed environmental soil conditions were studied in $40 \%$ of papers, $22 \%$ of the studies concerned the inoculation in relation to environmental stresses, and another $22 \%$ examined inoculation under nutrient deficient conditions (Figure 2). Moreover, 13\% of studies referred to polluted with heavy metal soils or soils with surpluses of other elements. At last, few cases concerned the role of inoculation in the biological control of diseases (3\%). Due to the large contribution of PGPR (45\%) and endophytes (20\%) to microbial inoculation of fodder plants, further we focused to these two subcategories. We didn't analyze extensively the AMF studies although they contributed by $22 \%$ to the total, because there was already a large literature body referring to AMF application to plants.

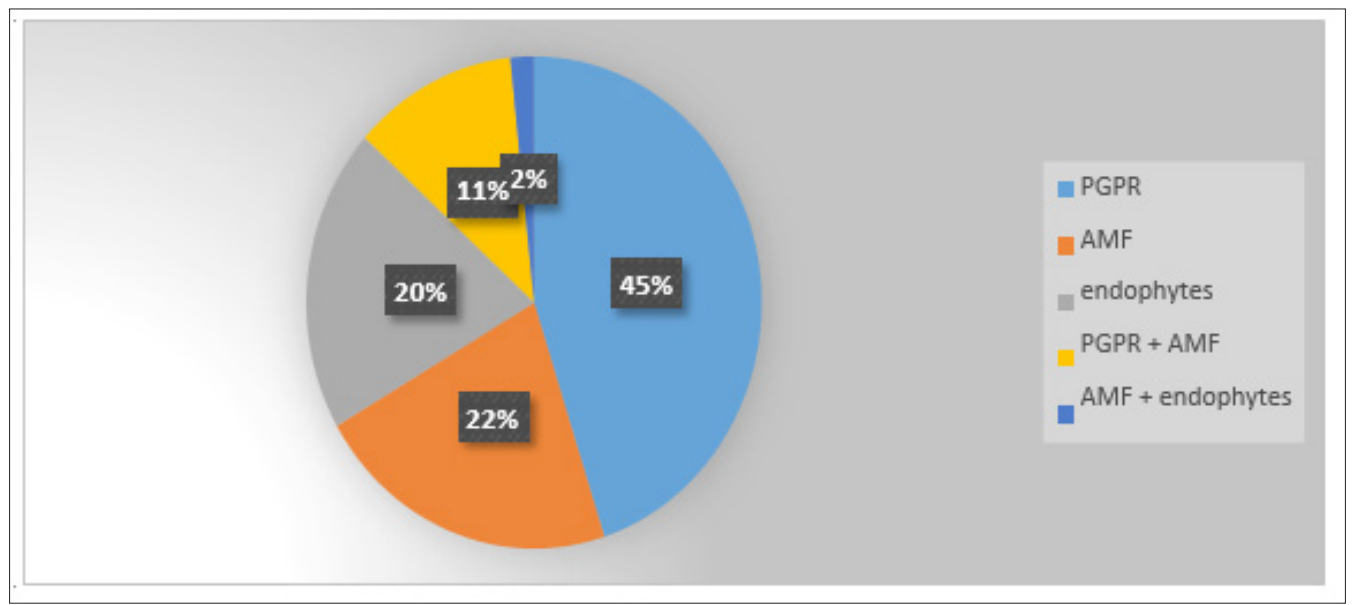

Figure 1: Percentage of studies referring to different types of inoculants used in the cultivation of fodder plants.

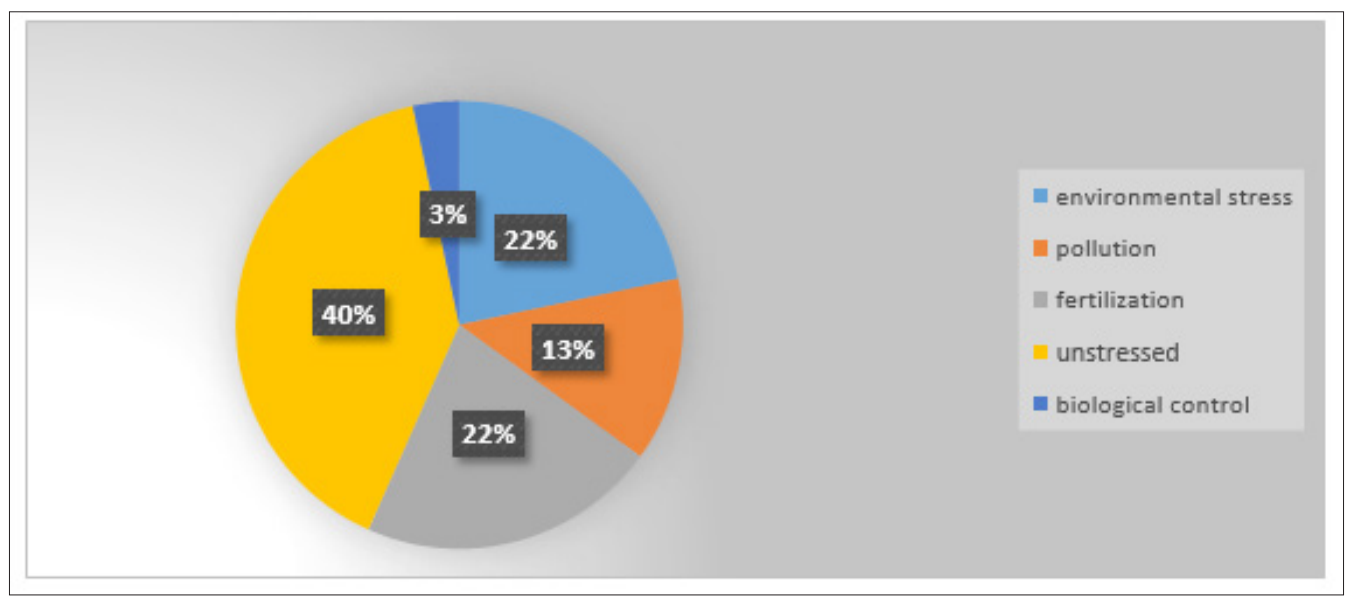

Figure 2: Percentage of studies concerning the specific conditions that the effects of microbial inoculants on fodder plants growth were examined.

\section{Plant Growth Promoting Rhizobacteria (PGPR)}

In recent years, farmers tend to replace the application of chemical fertilizers and pesticides with theinoculation of plants with PGPR due to the need for environmental protection and decrease of economic losses $[24,25]$. The effects of the application of PGPR on plants have been studied mainly in unstressed environmental conditions and in nutrient deficient conditions. They were studied to a lesser extent under conditions of environmental stress such as drought or salinity or in metal polluted soils (Table 1). The main interest of these studies was focused on the effectiveness of the inoculants on growth promotion, yield enhancement and nutritional quality improvement [26]. The development and yield production of a plant is correlated with the absorption of N, P and Zn. In soils with limited concentrations of these elements, plant growth, productivity and seed germination were inhibited [13,24,27,28,29]. Phosphorous is a main macronutrient for the completion of plants' biological functions but soil P is mainly immobilized and becomes unavailable to the plants $[24,28]$. Moreover, deficiency of $\mathrm{Zn}$, another essential element, limits not only the crop production but also the nutritional quality of the plants [29]. The action of PGPR in nutrient deficient soils has been studied in many laboratory or field experiments. The application of phosphate solubilizing bacteria (PSB) resulted in the increase of $\mathrm{P}$ uptake in plants as maize, wheat and wheat.

\section{Nutrient availability}

Especially PGPR of the genera Rhodococcus, Pseudomonas and Arthrobacter, enhanced the maize dry biomass and 
increased the $\mathrm{P}$ content of roots and shoot [27]. Same results were also revealed by the application of other bacteria such as Achromobacter spp., Agroacterium spp., Bordetella spp., Cupravidus spp., Ochrobactrum spp., Chryseobacterium spp. and Flavobacterium spp. [30]. Inoculation with Pantoea cypripedii and Pseudomonas plecoglossicida in maize and wheat increased $\mathrm{P}$ concentrations in grain, root and shoot, enhanced the shoot length, the grain yield and the dry biomass of the plants and also contributed to soil fertility by improving the availability of $\mathrm{P}$, the enzymatic action and the population of phosphate solubilizing bacteria $[17,24]$. The above results were also confirmed after the inoculation of wheat with phosphate solubilizing bacterial strains that were isolated from various soils in order to investigate their effects on wheat growth and nutrition [28].

Table 1: The application of PGPR on fodder plants.

\begin{tabular}{|c|c|c|c|}
\hline Crop species & Microbial Inoculants & Conditions & Source \\
\hline Maize & Bacillus spp. & fertilization & [26] \\
\hline Maize & Pseudomonas fluorescens, Enterobacter radicincitans & fertilization & [17] \\
\hline Maize & Rhodococcus spp., Pseudomonas spp., Arthrobacter spp., Burkholderia spp. & fertilization & [27] \\
\hline Maize-Wheat & Pantoea cypripedii, Pseudomonas plecoglossicida & fertilization & {$[24]$} \\
\hline Wheat & Rhodococcus spp., Pseudomonas spp, Arthrobacter nicotinovorans & fertilization & [28] \\
\hline Soybean, wheat & Bacillus aryabhattai & ferilization & [29] \\
\hline Wheat & Trabusiella spp., Aeromonas spp., Arthrobacter spp., Exiguobacterium aurantiacum & fertilization & [25] \\
\hline Wheat & Aneurinibacillus aneurinilyticus, Aeromonas spp., Pseudomonas spp. & fertilization & [30] \\
\hline Maize & Pseudomonas striata & drought stress & [31] \\
\hline Maize & Pseudomonas putida strain FBKV2 & drought stress & {$[32]$} \\
\hline Maize & Azospirillum spp. & drought stress & [33] \\
\hline Wheat & $\begin{array}{c}\text { Bacillus spp., Halobacillus spp., Bacillus gibsonii, Staphylococcus succinus, Zhihengliuella } \\
\text { spp., Zhihengliuella halotolerans, Oceanobacillus spp., Oceanobacillus oncorhynchi, Exig- } \\
\text { uobacterium aurantiacum, Bacillus atrophaeus, Halomonas spp., Virgibacillus picturae, } \\
\text { Thalassobacillus spp. }\end{array}$ & salinity & [34] \\
\hline Barley & Hartmannibacter diazotrophicus & salinity & [35] \\
\hline Barley & $\begin{array}{l}\text { Pseudomonas spp., Bacillus simplex, Curtobacterium flaccumfaciens, Ensifer garaman- } \\
\text { ticus, Microbacterium natoriense, Streptomyces spp, Hartmannibacter diazotrophicus, } \\
\text { Sphingopyxis taejonensis, Rheinheimera hassiensis, Cellvibrio diazotrophicus }\end{array}$ & salinity & [36] \\
\hline \multirow[b]{2}{*}{ Soybean } & Bradyrhizobium spp. & temperature stress & [37] \\
\hline & Enterobacter ludwigii & pollution & [38] \\
\hline
\end{tabular}




\begin{tabular}{|c|c|c|c|}
\hline Maize & $\begin{array}{l}\text { Anabaena spp., Anabaena torulosa, Nostoc carneum, Nostoc piscinale, Anabaena dol- } \\
\text { iolum, Providencia spp., Azotobacter chroococcum, Trichoderma viride }\end{array}$ & non-stress & [13] \\
\hline Maize & Pseudomonas spp., Enterobacter spp., Klebsiella spp. & non-stress & [19] \\
\hline Maize & Azospirillum brasilense & non-stress & [39] \\
\hline Maize & Azospirillum brasilense, Pseudomonas fluorescens & non-stress & [16] \\
\hline Wheat & $\begin{array}{c}\text { Azotobacter chroococcum, Mesorhizobium ciceri, Pseudomonas striata, Serratia marc- } \\
\text { escens }\end{array}$ & non-stress & [40] \\
\hline Wheat & Azospirillum spp., Azoarcus spp. and Azorhizobium spp. & non-stress & [41] \\
\hline Wheat & Providencia spp., Anabaena spp., Calothrix spp. & non-stress & [42] \\
\hline Wheat & Bacillus megaterium, Arthrobacter chlorophenolicus and Enterobacter spp. & non-stress & [43] \\
\hline Barley & Microbial $\mathrm{N}$-acyl-homoserine lactones & non-stress & [44] \\
\hline & Bacillus amyloliquefaciens, Bradyrhizobium japonicum & non-stress & [45] \\
\hline Soybean & $\begin{array}{c}\text { Achromobacter spp., Agrobacterium spp., Bordetella spp., Cupriavidus spp., Ochrobactrum } \\
\text { spp., Pseudoxanthomonas spp., Stenotrophomonas spp., Chryseobacterium spp., Flavobac- } \\
\text { terium genera }\end{array}$ & non-stress & [46] \\
\hline
\end{tabular}

On the other hand, Enterobacter radicincitans proved to have a drawback on $\mathrm{P}$ availability and yield production [17]. PGPR as Acinetobacter spp., Bacillus spp., Gluconacetobacter spp., Pseudomonas spp., Trabusiella spp., Aeromonas spp., Arthrobacter spp., and Exiquobacterium spp. are considered zinc solubilizing bacteria [25,29]. $\mathrm{Zn}$ is essential for plants as it is a part of over 300 proteins, playing an important role in enzymatic activity and the production of auxins in plants, although it appears to be toxic for plants and animals in great amounts [30]. The solubilization of $\mathrm{Zn}$ is promoted by the production and secretion of many acids, hormones and vitamins [26,29]. These strains are capable of enhancing growth and yield and improving quality of the crops. Specifically, the application of Bacillus aryabhattai on soybean and wheat increased the $\mathrm{Zn}$ content in broths, enhanced the solubilization of $\mathrm{Zn}$ and this resulted in improved seed yield, root and shoot dry weight and increased Zn concentrations in plants [29].

Moreover, as for the production of IAA (Indole-3-Acetic Acid) and siderophores, some strains of Bacillus spp. revealed a positive reaction, but for the increased production of IAA, the simultaneous presence of L-tryptophan and PGPRgave greater results [26]. Bacillus spp. promoted also the growth of plants, as the measurements for shoot and root length, shoot, root and total fresh and dry biomass showed significant improvement [26]. Except from quantitative effects, Zn solubilizing bacteria offer also qualitative profit to plants as they enhance the amounts of micronutrients such as Zn, Fe, N, P and $\mathrm{K}$ in plant tissues [25]. Additionally, Kumar et al. [31] revealed the importance of Fe for plant growth, as the enhanced siderophore production by bacterial strains of Aneurinibacillus aneurinilyticus, Aeromonas spp. and Pseudomonas spp. resulted in increased seed germination, plant height, and total dry weight of wheat plants
[31]. Some of these strains revealed also an action against Fusarium solani, a pathogenic agent of wheat.

\section{Protection against environmental stress}

The inoculation of plants with PGPR, promotes the protection against environmental stresses such as drought, salinity and extreme temperatures that inhibit the growth of agricultural crops [32,33]. Experiments took place in Iraq and Pakistan in order to investigate the effect of application of plant residues and P-solubilizing bacteria, mainly Pseudomonas striata, along with the proper management of $\mathrm{P}$ on maize yield and its components [31]. The researchers found out that the application of bacteria or plant residue or phosphorus sources per se had significantly positive effects on yield variables such as total number of plants, ear length, number of grains per row or per ear, grain yield, harvest index and selling percentage [31]. However, the interactions of the applicants had no significant effects on plant yield and its components. Earlier, in 2016 in India, Vurukonda et al. [33] investigated the effects of the application of Pseudomonas putida strain FBKV2 in maize. It was revealed that this strain promoted the production of IAA, HCN (Hydrogen Cyanide), siderophore and the solubilization of $P$ under both control and drought conditions. Moreover, under drought stress conditions, inoculation with the strain FBKV2 increased the content of sugars, starch, proline, chlorophyll and amino acids contained in maize seedlings.

Additionally, the seedlings' growth was promoted as found by the increases in root and shoot length, the dry biomass, the metabolites presence and activity and the stomatal activity [32]. Moreover, the inoculation of maize with Azospirillum spp. in vitro, revealed that these bacteria and especially the strains Az39 and 
Az19 can offer osmotic, salt and drought tolerance to the plants by increasing the production of IAA and proline, by maintaining the water content at certain level resulting to the increase of the plant height and the dry weight of shoot and roots [33]. Additionally, the alleviation of salinity, an abiotic stress that might affect half of global agricultural soils by 2050 [34] by PGPR inoculation has been studied. The PGPR inoculation not only improved salinity tolerance but also enhanced the plant development [35]. The major mechanism of defense against salinity is the production of ACCdeaminase by bacterial strains [36]. ACC-deaminase producing bacteria manage to decrease the ethylene aggregation in plants under salt stress and promote plant development and elongation of roots [34].

Bacterial strains that alleviate salinity increased length, fresh and dry weight of aerial and root parts, root-to-shoot ratio and also the water content as proven by experiments in wheat and barley [34-36]. Especially, Hartmannibacter diazotrophicus also decreased the uptake of $\mathrm{Na}$ by the roots which led to the restoration of nutrient balance [36]. Moreover, soybean yield production has been increased after inoculation with Bradyrhizobium spp. strains and commercially available inoculants under cool conditions [37]. The rhizobium strains achieved to promote the highest grain yield and protein content in soybean varieties [37]. ACC-deaminase is a major cofactor for the alleviation from toxicity induced by increased concentration of heavy metals [38]. The inoculation of wheat with the Enterobacter ludwigii CDP-14 which is a Zn-resistant bacterium, increased the production of ACC-deaminase, IAA, and the solubilization of phosphates, factors that promote plant growth [38].

\section{The role of PGPR in non-stressed conditions}

The beneficial activity of PGPR application has also been studied under non-stressed environmental conditions. The availability of $\mathrm{N}$ in soil is essential for the enhancement of growth and productivity of plants [13]. Moreover, Na affects the mobility and the uptake of $\mathrm{P}$ and $\mathrm{Zn}$ while $\mathrm{N}$ availability enhances the translocation of nutrients between shoot and root [39]. In experiments with cyanobacteria strains in maize, Prasanna et. al. [13] found out that PGPR bacteria promote the crop production; plants became taller and cob yields were enhanced. Furthermore, they improved the soil functional activities and soil aggregation due to the increase of glomalin related soil proteins. Cyanobacteria based biofilms, that were inoculated together with bacteria Azotobacter chroococcum, Mesorhizobium cicero, Serratia marcecens and Pseudomonas striata increased the $\mathrm{N}$-fixing potential by increasing the acetylene reducing activity in pot experiments in wheat, promoting plant growth and production [40]. The application of consortium of Providencia spp. with cyanobacteria of genera Anabaena spp. and Calothrix spp. and a commercial fertilizer $\mathrm{N}_{60} \mathrm{P} 60 \mathrm{~K} 60$ enhanced at highest level the wheat grain yield [39]. The protein content and the concentration of essential micronutrients such as $\mathrm{Fe}, \mathrm{Cu}, \mathrm{Zn}$ and $\mathrm{Mn}$ was increased at the highest by the simultaneous implementation of Providencia spp. and the fertilizer mentioned above [39]. Especially, the individual application of Providencia spp. revealed the role of this PGPR in the production of $\mathrm{NH}_{3}$, siderophores, $\mathrm{HCN}$, indolic compounds and the solubilization of $\mathrm{P}$ and $\mathrm{Zn}$.

The application of Pseudomonas fluorescens has also been studied in experiments in maize and wheat along with nitrogen fertilization and the application of Azospirillum brasilense. Although the results showed no interactions between the fertilizers and the PGPR, the application of each of them individually or jointly resulted in the enhancement of grain yield and root biomass but decreased the aerial biomass of the plants. It was estimated that the aerial biomass decreased was due to P- deficiency as the main action of P. fluorescens is the solubilization of P [16]. The maize's total fresh and dry weight and the shoot length have been increased after the positive synergistic effect of Pseudomonas spp., Enterobacter spp. and Klebsiella spp [19]. This study also revealed that after years of continuous bacterial application on the same field, maize growth exhibited efficient improvement [19]. Azospirillum brasilense, which is a non-symbiotic PGPR, was also studied on maize, either at sowing on seed or as leaf spray at the V3 stage of plant growth in combination with metabolites of Rhizobium tropici [39]. Both ways of application resulted in increased grain yield, $\mathrm{N}$ uptake and shoot dry weight [39].

However, it was found out that the shoot dry weight was increased only by the individual application of $A$. brasilense on seed, whereas when applied as spray on leaves, the enrichment with metabolites of $R$. tropici was needed for this increase [39]. According to the study of Cortivo et al. [41] soil application or foliar spraying of PGPR N-fixing bacteria improved wheat's root parameters; length and surface area. Specifically, the application of Azospirillum spp., Azoarcus spp., and Azorhizobium spp. along with a commercial bio-fertilizer improved root growth, increase the resistance of plants to stress and reduced $\mathrm{N}$-losses offering enhancement of grain yield. The promotion of growth, yield and nutrient uptake in wheat has also been proved after the inoculation in pot and field experiments with Bacillus megaterium, Arthrobacter chlorophenolicus and Enterobacter spp., bacteria that promote $\mathrm{N}$-fixation, $\mathrm{P}$ solubilization and HCN and siderophore production [31]. The application of this triple consortium enhanced the plant height, the grain and straw yield and maximized the $\mathrm{Zn}, \mathrm{Fe}, \mathrm{Cu}$ and Mn concentrations in wheat plants in both pot and field conditions. Also, all individual applications of these bacteria resulted in increased grain yield which shows that this improvement is a result of higher nutrient concentration in soil and plant [31]. PGPR also promote $\mathrm{K}^{+}$uptake by plants which is another essential element for plant's life cycle [42]. Especially, the effect of N-acyl-homoserine lactones (AHLs) on growth promotion, root development and $\mathrm{K}^{+}$ uptake was studied in barley [42]. They promoted root elongation and increased the number of tips per root system, changing the root architecture which resulted in increased uptake of K cations. This consequently enhanced the plant biomass. In soybean, the application of Bacillus amyloliquefaciens subsp. plantarum with Bradyrhizobium japonicum, a soybean microsymbiont resulted in growth promotion due to the production of great levels of auxin, gibberellins and salicylic acid by the Bacillus and the increase of nitrogen fixation by the microsymbiont [43]. 


\section{Endophytes}

Endophytes are microbial organisms that live inside the plant for a part of their life cycle without acting harmfully or gaining benefit from the plant [44-46]. Some of the most abundant endophytes belong to the genera Pseudomonas, Bacillus, Burkholderia, Stenotrophus, Micrococcus, Pantoea and Microbacterium [47]. Some of them act beneficially for their hosts by increasing metabolic activity, promoting the root development, the availability of nutrients and the tolerance to toxic compounds [47]. Moreover, they promote plant growth by the production of phytohormones as auxins, cytokinins and gibberelins [48]. In experiments in maize, the positive effect of endophytes on $\mathrm{N}$-fixation has been displayed $[46,48]$. Paenibacillus polymixa strain P2b-2R assisted in the use of $\mathrm{N}$ from the atmospheric $\mathrm{N}$ pool and promoted plant development by increasing the shoot and the seedling length and maize's biomass [46]. Paenibacillus spp. unveiled its effect on $\mathrm{N}$-fixation and its antipathogenic action on maize, in experiments where endophytic bacteria isolated from the rhizosphere of Jatropha curcas [48]. Bacillus spp., Paenibacillus spp., Brevibacillus spp., Sphingomonas spp., Rhizobium spp., Teribacillus spp. and Staphylococcus spp. promoted maize's growth mainly by the production of IAA, ACC deaminase, N-fixation, the activity of phosphatase and the solubilization of $\mathrm{P}$ and $\mathrm{K}$ [48] (Table 2).

Table 2: Endophytes' application on fodder plants.

\begin{tabular}{|c|c|c|c|}
\hline Crop species & Inoculants & Conditions & Source \\
\hline Maize & Burkholderia phytofirmans strain PsJN, Enterobacter spp. strain FD17 & drought & [48] \\
\hline Maize & Gaeumannomyces cylindrosporus & pollution & {$[51]$} \\
\hline Wheat & Paenibacillus spp., Enterobactereaceae of Pantoea and Fictibacillus/Bacillus spp. & biological control & [53] \\
\hline Wheat & Paenibacillus spp. and Curtobacterium plantarum & biological control & [21] \\
\hline Maize & $\begin{array}{l}16 \text { S rRNA genes mainly homologous to Bacillus spp., Paenibacillus spp., Brevibacillus spp., } \\
\text { Sphingomonas spp., Staphylococcus spp., Teribacillus spp. and Rhizobium spp. }\end{array}$ & non-stress & {$[52]$} \\
\hline Maize & Paenibacillus polymyxa & non-stress & {$[50]$} \\
\hline Wheat, Sorghum & Streptomyces spp. & non-stress & [54] \\
\hline Wheat & $\begin{array}{l}31 \text { nitrogen fixing endophytic bacteria affiliated to Actinobacteria, Proteobacteria and Fir- } \\
\text { micutes representing } 14 \text { genera, mainly Arthrobacter spp., Rhizobium spp., and Bacillus spp. }\end{array}$ & non-stress & [49] \\
\hline Wheat & Azospirillum brasilense, Achromobacter insolitus, Zooglea ramigera & non-stress & [55] \\
\hline Barley & Paenibacillus spp., Pantoea spp. and Pseudomonas spp. & non-stress & [56] \\
\hline Soybean & $\begin{array}{l}\text { Enterobacter cloacae, Acinetobacter calcoacetius, Pseudomonas putida, Ochrobactrum hae- } \\
\text { matophilum, Bacillus amyloliquefaciens and Bacillus cereus }\end{array}$ & non-stress & [57] \\
\hline Soybean & Beauveria bassiana, Metarhizium anisopliae and Metarhizium robertsii & non-stress & [58] \\
\hline
\end{tabular}

Also, the importance of siderophores in mineral uptake and that of $\mathrm{P}$ solubilization on $\mathrm{K}$ accumulation were confirmed. Inoculation of wheat with endophytes, resulted in nutrient solubilization, development of plants and in some cases in protective activity against diseases $[21,43,45,49]$. Foliar inoculation with Streptomyces spp. resulted in extensive colonization of wheat plants, increased the biomass of their belowground parts, shoot weight and also impeded the infection and activity of Rhizoctonia solani and Magnaporte oryzae [49], [49]. Moreover, in greenhouse experiments, inoculation with Azospirillum brasilense, Achromobacter insolitus and Zooglea ramigera increased the chlorophyll content of plants, the root and shoot biomass and also promoted the production of IAA and $\mathrm{N}$-fixation. Especially, they increased glutamine synthetase which is a major enzyme in the assimilation of $\mathrm{NH}_{4}{ }^{+}$, contributed mostly in grain growth and $\mathrm{N}$-content of shoots [50]. Endophytic bacteria of phylum Actinobacteria, Proteobacteria and Firmicutes promoted plant growth and the production of IAA and siderophores [45].
Bacteria of Acinetobacter phylum were indicated as P-solubilizers enhancing the uptake of this essential element [45]. The protective role of endophytes, especially of Paenibacillus spp., was reported in experiments in 2016 and 2017 [21,51]. The inoculation of wheat plants with Paenibacillus spp., Pantoea spp., and Fictibacillus spp., resulted in the promotion of plant development and the increased production of antifungal substances that acted towards the suppression of Fusarium graminarum [51]. Paenibacillus spp. has the ability to produce lipopeptides with antibiotic action called paenymixins. Paenibacillus spp. strain B2 and Curtobacterium plantarum EDS were applied on wheat plants and the production of paenymixins resulted to the induction of resistance against the pathogenic Mycosphaerella graminicola which causes the septoria leaf blotch disease [21]. In barley, the inoculation with Paenibacillus spp, Pseudomonas spp., and Pantoea spp. had positive effects on plant development, mineral nutrition and defense mechanisms [52]. Especially, under harsh conditions, these microorganisms 
managed to increase plant height, chlorophyll content, water content and the concentration of essential elements as $\mathrm{K}$ and $\mathrm{Mg}$, while induced resistance against Blumeria graminis. The effects of application of endophytic inoculants were also examined in soybean plants [53,54]. Enterobacter clocae, Acinetobacter calcoaceticus, Pseudomonas putida, Bacillus spp., Beauveria bassiana, and Metarhizium spp., have the ability to promote N-fixation and the production of IAA and siderophores. Especially, results showed a positive interaction between siderophores and restriction of pathogenic Phytophthora sojae [53].

Bacillus spp., Acinetobacter spp. and Enterobacter spp., increased shoot and root length, the chlorophyll content and the plant's fresh weight [53]. Beauveria Bassiana and Metarhizium spp. were applied either as foliar spray or by immersion on seeds or roots. B. bassiana was inoculated by all techniques while Metarhizium spp. was not inoculated by seed immersion [54]. In B. bassiana the growth parameters were increased while the impact of insect pests or antagonistic pathogens on soybean plants was decreased. Endophytes alleviate also abiotic stress conditions or toxicity for plants [44,47]. Burkholderia phytofirmans and Enterobacter sp. FC17 minimized the impact of drought stress on maize and increased plant's biomass, photosynthesis and development [44] by affecting the photosynthetic rate, the conductance of stomata and transpiration, and the improvement of leaf water content. The inoculation of maize plants with Gaemannomyces cylindrosporus at $\mathrm{Pb}$ and $\mathrm{Zn}$-mine tailings, under greenhouse conditions revealed the ability of this endophyte to promote plant development and the accumulation of these metals [47]. Moreover, the inoculation promoted the $\mathrm{Pb}$ accumulation and its translocation to shoots, which mainly decreased the toxic effect of $\mathrm{Pb}$ [55-59].

\section{Future perspectives}

This review identified three gaps in the research concerning the application of microbial inoculants in the cultivation of fodder plants. These are the following:

A. From a total of 72 studies, 60 referred to the impact of microbial inoculation on four (maize, wheat, barley and soybean) out of the eight crop species (trefoil, alfalfa, oats and sorghum) that are used for livestock farming.

B. Inoculants have been tested for their effects as biofertilizers but not as biopesticides. Only 3\% of the studies examined the role of microbes as protective agents against diseases and these are related to endophytes' application.

C. A combination of different microbial strains/species that are usually belong to the same microbial group (PGPR or endophytes) were tested. Studies referring to the jointly effects of microbes of different microbial groups were minority.

The study of these gaps should guide future research in the area of fodder plants cultivation.

\section{References}

1. Bongaarts $J$ (2009) Human population growth and the demographic transition. Philos Trans R Soc Lond B Biol Sci 364(1532): 2985-2990.
2. Alexandratos N (1999) World food and agriculture: outlook for the medium and longer term. Proc Natl Acad Sci USA 96(11): 5908-5914.

3. Ruttan VW (2002) Productivity growth in world agriculture: sources and constraints. J Econ Perspec 16(4): 161-184.

4. Miflin B (2000) Crop improvement in the 21st century. J Exper Bot 51(342): 1-8.

5. Voutsinos G, Papageorgiou K, Kaldis P, Polydwros V, Vitwratos A, et al. (1999) Agronomy and rural development data. School Book Publishing Organization, Greek Ministry of Education, Research and Religious Afffairs.

6. Black JL (2001) Variation in nutritional value of cereal grains across livestock species. Proc Australian Poultry Science Symposium 13: 22-29.

7. Egan AR (2017) Animal nutrition and feed science. Engineering 3(5): 586-587.

8. (2000) FAO: Food and agriculture organization of the United Nations, Crops and Drops, Rome, Italy.

9. (2015) FAO, Food and agriculture organization. Statistical Yearbook of FAO, FAO Publications, Rome, Italy.

10. Garnett T (2010) Intensive versus extensive livestock systems and greenhouse gas emissions. Food Climate Research Network briefing paper.

11. Hanson AA, DK Barnes, RR Hill (1988) Alfalfa and alfalfa improvement (Agronomy). Publisher, Amer Society of Agronomy.

12. Tekeli AS, Ates E, Varol F (2005) Nutritive values of some annual clovers (Trifolium sp.) at different growth stages. J Central Eur Agric 6(3): 323330.

13. Prasanna R, Kanchan A, Ramakrishnan B, Ranjan K, Venkatachalam S, et al. (2016) Cyanobacteria-based bioinoculants influence growth and yields by modulating the microbial communities favourably in the rhizospheres of maize hybrids. Eur J Soil Biol 75: 15-23.

14. Calvo P, Nelson L, Kloepper JW (2014) Agricultural uses of plant biostimulants. Plant \& Soil 383(1-2): 3-41.

15. Gómez OC, Luiz JHH (2018) Endophytic fungi isolated from medicinal plants: future prospects of bioactive natural products from Tabebuia/ Handroanthus endophytes. Appl Microbiol Biotech 102(21): 9105-9119.

16. Di Salvo LP, Cellucci GC, Carlino ME, García de Salamone IE (2018) Plant growth-promoting rhizobacteria inoculation and nitrogen fertilization increase maize (Zea mays L.) grain yield and modified rhizosphere microbial communities. Appl Soil Ecol 126: 113-120.

17. Krey T, Vassilev N, Baum C, Eichler löbermann B (2013) Effects of longterm phosphorus application and plant-growth promoting rhizobacteria on maize phosphorus nutrition under field conditions. Eur J Soil Biol 55: 124-130.

18. Rouphael Y, Franken P, Schneider C, Schwarz D, Giovannetti M, et al. (2015) Arbuscular mycorrhizal fungi act as biostimulants in horticultural crops. Sci Hortic 196: 91-108.

19. Ibañez F, Arroyo M E, Angelini J, Tonelli ML, Muñoz V, et al. (2014) Non-rhizobial peanut nodule bacteria promote maize (Zea mays $L$.) and peanut (Arachis hypogaea L.) growth in a simulated crop rotation system. Appl Soil Ecol 84: 208-212.

20. Rashid MI, Mujawar LH, Shahzad T, Almeelbi T, Ismail IMI, et al. (2016) Bacteria and fungi can contribute to nutrients bioavailability and aggregate formation in degraded soils. Microbiol Res 183: 26-41.

21. Samain E, van Tuinen D, Jeandet P, Aussenac T, Selim S (2017) Biological control of septoria leaf blotch and growth promotion in wheat by Paenibacillus sp. strain B2 and Curtobacterium plantarum strain EDS. Biol Control 114: 87-96.

22. Hildebrandt U, Regvar M, Bothe H (2007) Arbuscular mycorrhiza and heavy metal tolerance. Phytochemistry 68(1): 139-146. 
23. Lenoir I, Fontaine J, Hadj Sahraoui AL (2016) Arbuscular mycorrhizal fungal responses to abiotic stresses: A review. Phytochemistry 123: 4-15.

24. Kaur G, Reddy MS (2015) Effects of phosphate-solubilizing bacteria, rock phosphate and chemical fertilizers on maize-wheat cropping cycle and economics. Pedosphere 25(3): 428-437.

25. Shaikh S, Saraf M (2017) Biofortification of Triticum aestivum through the inoculation of zinc solubilizing plant growth promoting rhizobacteria in field experiment. Biocatal Agric Biotechnol 9: 120-126.

26. Mumtaz MZ, Ahmad M, Jamil M, Hussain T (2017) Zinc solubilizing Bacillus spp. potential candidates for biofortification in maize. Microbiol Res 202: 51-60.

27. Pereira SIA, Castro PML (2014) Phosphate-solubilizing rhizobacteria enhance Zea mays growth in agricultural P-deficient soils. Ecol Eng 73 526-535.

28. Ramesh A, Sharma SK, Sharma MP, Yadav N, Joshi OP (2014) Inoculation of zinc solubilizing Bacillus aryabhattai strains for improved growth, mobilization and biofortification of zinc in soybean and wheat cultivated in Vertisols of central India. Appl Soil Ecol 73: 87-96.

29. Batool S, Iqbal A (2018) Phosphate solubilizing rhizobacteria as alternative of chemical fertilizer for growth and yield of Triticum aestivum (Var. Galaxy 2013). Saudi J Biol Sci.

30. Bassey Y, Mitsumoto H, Sakamoto K (2017) Bradyrhizobia and arbuscular mycorrhizal fungi modulate manganese, iron, phosphorus, and polyphenols in soybean (Glycine max (L.) Merr) under excess zinc. Environ and Exper Bot 137: 1-13.

31. Kumar P, Thakur S, Dhingra GK, Singh A, Pal MK, et al. (2018) Inoculation of siderophore producing rhizobacteria and their consortium for growth enhancement of wheat plant. Biocatalysis and Agricultural Biotechnology 15: 264-269.

32. Iqbal A, Amanullah Song M, Shah Z, Alamzeb M, Iqbal M (2018) Integrated use of plant residues, phosphorus and beneficial microbes improve hybrid maize productivity in semiarid climates. Acta Ecol Sinica.

33. Vurukonda SSKP, Vardharajula S, Shrivastava M, SkZ A (2016) Multifunctional Pseudomonas putida strain FBKV2 from arid rhizosphere soil and its growth promotional effects on maize under drought stress. Rhizosphere 1: 4-13.

34. Suarez C, Cardinale M, Ratering S, Steffens D, Jung S, et al. (2015) Plant growth-promoting effects of Hartmannibacter diazotrophicus on summer barley (Hordeum vulgare L.) under salt stress. Applied Soil Ecology 95: 23-30.

35. García JE, Maroniche G, Creus C, Suárez Rodríguez R, Ramirez Trujillo JA et al. (2017) In vitro PGPR properties and osmotic tolerance of different Azospirillum native strains and their effects on growth of maize under drought stress. Microbiol Res 202: 21-29.

36. Orhan F (2016) Alleviation of salt stress by halotolerant and halophilic plant growth- promoting bacteria in wheat (Triticum aestivum). Braz J Microbiol 47(3): 621-627.

37. Cardinale M, Ratering S, Suarez C, Maria A, Montoya Z, et al. (2015) Paradox of plant growth promotion potential of rhizobacteria and their actual promotion effect on growth of barley (Hordeum vulgare L.) under salt stress. Microbiol Res 181: 22-32.

38. Zimmer S, Messmer M, Haase T, Piepho H, Mindermann A, et al. (2016) Effects of soybean variety and Bradyrhizobium strains on yield, protein content and biological nitrogen fixation under cool growing conditions in Germany. Eur J Agron 72: 38-46.

39. Rana A, Joshi M, Prasanna R, Shivay YS, Nain L (2012) Biofortification of wheat through inoculation of plant growth promoting rhizobacteria and cyanobacteria. Eur J Soil Biol 50: 118-126.
40. Swarnalakshmi K, Prasanna R, Kumar A, Pattnaik S, Chakravarty K, et al. (2013) Evaluating the influence of novel cyanobacterial biofilmed biofertilizers on soil fertility and plant nutrition in wheat. Eur J Soil Biol 55: 107-116.

41. Cortivo CD, Barion G, Visioli G, Mattarozzi M, Mosca G (2017) Increased root growth and nitrogen accumulation in common wheat following PGPR inoculation. Assessment of plant-microbe interactions by ESEM. Agric Ecosyst Environ 247: 396-408.

42. Rankl S, Gunsé B, Sieper T, Schmid C, Poschenrieder C, Schröder P (2016) Microbial homoserine lactones (AHLs) are effectors of root morphological changes in barley. Plant Sci 253: 130-140.

43. Masciarelli O, Llanes A, Luna V (2014) A new PGPR co-inoculated with Bradyrhizobium japonicum enhances soybean nodulation. Microbiol Res 169(7-8): 609-615.

44. Naveed M, Mitter B, Reichenauer TG, Wieczorek K, Sessitsch A (2014) Increased drought stress resilience of maize through endophytic colonization by Burkholderia phytofirmans PsJN and Enterobacter sp. FD17. Environ Exper Bot 97: 30-39.

45. Patel JK, Archana G (2017) Diverse culturable diazotrophic endophytic bacteria from Poaceae plants show cross-colonization and plant growth promotion in wheat. Plant and Soil 417(1-2): 99-116.

46. Puri A, Padda KP, Chanway, CP (2015) Can a diazotrophic endophyte originally isolated from lodgepole pine colonize an agricultural crop (corn) and promote its growth? Soil Biol Biochem 89: 210-216.

47. Ban Y, Xu Z, Yang Y, Zhang H, Chen H, et al. (2017) Effect of Dark Septate Endophytic Fungus Gaeumannomyces cylindrosporus on Plant Growth, Photosynthesis and $\mathrm{Pb}$ Tolerance of Maize (Zea mays L.). Pedosphere 27(2): 283-292.

48. Mohanty SR, Dubey G, Kollah B (2016) Endophytes of Jatropha curcas promote growth of maize. Rhizosphere 3: 20-28.

49. Patel JK, Madaan S, Archana G (2018) Antibiotic producing endophytic Streptomyces spp. colonize above-ground plant parts and promote shoot growth in multiple healthy and pathogen-challenged cereal crops. Microbiol Res 215: 36-45.

50. Parada A, Marino V, Sala R, Jurandy E, Nogueira B, et al. (2016) Nitrogen metabolism and growth of wheat plant under diazotrophic endophytic bacteria inoculation. Appl Soil Ecol 107: 313-319.

51. Díaz Herrera S, Grossi C, Zawoznik M, Groppa MD (2016) Wheat seeds harbour bacterial endophytes with potential as plant growth promoters and biocontrol agents of Fusarium graminearum. Microbiol Res 186187: $37-43$.

52. Rahman M, Flory E, Koyro H, Abideen Z, Schikora A, et al. (2018) Consistent associations with beneficial bacteria in the seed endosphere of barley (Hordeum vulgare L.). Syst Appl Microbiol 41(4): 386-398.

53. Zhao L, Xu Y, Lai X (2017) Antagonistic endophytic bacteria associated with nodules of soybean (Glycine max L.) and plant growth-promoting properties. Braz J Microbiol 49(2): 269-278.

54. Russo ML, Pelizza SA, Vianna MF, Allegrucci N, Cabello MN, et al. (2018) Effect of endophytic entomopathogenic fungi on soybean Glycine max (L.) Merr. growth and yield. J King Saud Univ Sci.

55. Singh RP, Mishra S, Jha P, Raghuvanshi S, Jha PN (2018) Effect of inoculation of zinc-resistant bacterium Enterobacter ludwigii CDP-14 on growth, biochemical parameters and zinc uptake in wheat (Triticum aestivum L.) plant. Ecol Eng 116: 163-173.

56. Marks BB, Megías M, Ollero FJ, Nogueira MA, Araujo RS, et al. (2015) Maize growth promotion by inoculation with Azospirillum brasilense and metabolites of Rhizobium tropici enriched on lipo-chitooligosaccharides (LCOs). AMB Express 5(1): 71. 
57. Cortivo CD, Barion G, Visioli G, Mattarozzi M, Mosca G (2017) Increased root growth and nitrogen accumulation in common wheat following PGPR inoculation. Assessment of plant-microbe interactions by ESEM. Agric Ecosyst Environ 247: 396-408.

58. Kumar A, Maurya BR, Raghuwanshi R (2014) Isolation and characterization of PGPR and their effect on growth, yield and nutrient content in wheat (Triticum aestivum L.). Biocatal Agric Biotechnol 3(4): 121-128.
59. Youseif SH (2018) Genetic diversity of plant growth promoting rhizobacteria and their effects on the growth of maize plants under greenhouse conditions. Annals Agric Sci 63(1): 25-35. 